\title{
Epidemiology and management of chronic renal failure: a global public health problem
}

\author{
Adekunle Sanyaolu, ${ }^{2}$ Chuku Okorie, ${ }^{2}$ Rochelle Annan, ${ }^{3}$ Hanin Turkey, ${ }^{3}$ Nofil Akhtar, ${ }^{3}$ Fernanda Gray, ${ }^{3}$ \\ Kareem Hamdy, ${ }^{3}$ Ainura Isina, ${ }^{3}$ Gajendra Maharjan, ${ }^{3}$ Watik Maghroudi, ${ }^{3}$ Ifeanyi Chukwu Nwaduwa ${ }^{3}$ \\ 'Federal Ministry of Health, Abuja, Nigeria \\ ${ }^{2}$ Essex County College, Newark, New Jersey, USA \\ ${ }^{3}$ Saint James School of Medicine, Anguilla, BVI
}

Correspondence: Dr Adekunle Sanyaolu, Federal Ministry of Health,Abuja, Nigeria, Email sanyakunle@gmail.com

Received: February 02, 2018 | Published: February 26, 2018

Copyright@ 2018 Sanyaolu et al. This is an open access article distributed under the terms of the Creative Commons Attribution License, which permits unrestricted use, distribution, and reproduction in any medium, provided the original author and source are credited.

\begin{abstract}
Chronic kidney disease is an emergent worldwide public health problem. The increasing incidence of chronic renal failure warrants a need for an epidemiological approach to better understand the disease and its prevention. While statistics have been identified concerning world demographics, there is not enough information on how to better prevent and screen for this disease. There is evidence on the global distribution suggesting that chronic renal failure is a growing issue in developed and developing countries. While screening and intervention can prevent chronic kidney disease, awareness of the disorder, however, remains low in many communities and among many healthcare workers hence, this paper explores the epidemiology, diagnosis, treatment and management of chronic kidney disease.
\end{abstract}

Keywords: epidemiology, chronic kidney diseases, glomerular filtration rate, end-stage renal disease

\section{Introduction}

Disease morbidity and mortality patterns all over the world are changing, both in the developed and the emerging world. Throughout the $20^{\text {th }}$ century, infectious diseases were the major cause of death and disability. Nonetheless in this century, non-communicable, noninfectious diseases have become the main cause of mortality and morbidity around the world. ${ }^{1}$ This change is mirrored in the type of diseases causing chronic kidney failure and in their presentation and progression. $^{2}$

Kidney disease is evaluated in terms of overall renal function (glomerular filtration rate, GFR) and the presence of kidney damage established by either kidney biopsy or other markers of kidney damage. ${ }^{3}$ Chronic kidney disease (CKD) is a common condition in which there is a loss of kidney function over time. CKD is associated with increased risks of several co morbidities; not limited to but including cardiovascular disease and chronic renal failure. ${ }^{4}$

Chronic kidney disease is an emergent worldwide public health problem. In the United States, the prevalence of end-stage renal disease (ESRD) is increasing. ${ }^{5} \mathrm{CKD}$ is increasingly common in developed and developing nations. ${ }^{2}$

Screening and intervention can prevent chronic kidney disease, and where management strategies have been implemented the incidence of end-stage kidney disease has been reduced. Awareness of the disorder, however, remains low in many communities and among many physicians. ${ }^{6}$
There is a greater need in understanding of the mechanisms underlying renal scarring leading to ESRD to advise on current and future interventions as well as evidence relating to interventions to slow the progression of CKD. Strategies to reduce burden and costs related to chronic kidney disease need to be included in national programs for non-communicable diseases. ${ }^{6}$ This paper aimed at exploring the epidemiology, diagnosis, treatment and management of chronic kidney disease.

\section{Methodology}

A literature search for chronic kidney diseases (CKD) and end stage renal diseases (ESRD) was carried out. Articles were retrieved by performing searches using online electronic databases (Pub Med, Medline plus, Mendeley, Google Scholar, Research Gate, Global Health and Scopus). Articles were streamlined to epidemiology and management of CKD and ESRD. Titles and abstracts of these results were reviewed and selected for inclusion based on relevancy to the research question. Overall, 30 articles and references were utilized for the study.

\section{Epidemiology: incidence and prevalence of chronic renal failure}

The growth of the population with ESRD is related to under recognition of earlier stages of Chronic Kidney Disease. The incidence of ESRD 
being treated by dialysis varies enormously depending on the level of affluence of the country. The highly developed countries, such as North America, Europe and Japan have the highest incidence rate of ESRD (Figure 1). ${ }^{7}$ There are over 1 million dialysis patients worldwide, with an incidence of about a quarter million per year. In the United States, the overall prevalence of CKD increased from 12 percent to 14 percent between 1988 and 1994 and from 1999 to 2004 but has remained relatively stable since 2004 . The largest increase occurred in people with Stage $3 \mathrm{CKD}$, from 4.5 percent to 6.0 percent, since 1988. ${ }^{8}$ Also in the United States, incidence of CKD is increasing most rapidly in people ages 65 and older which more than doubled between 2000 and 2008 (Figure 2). ${ }^{9}$ The incidence among 20- to 64 -year-olds is less than 0.5 percent. ESRD incident rates are more

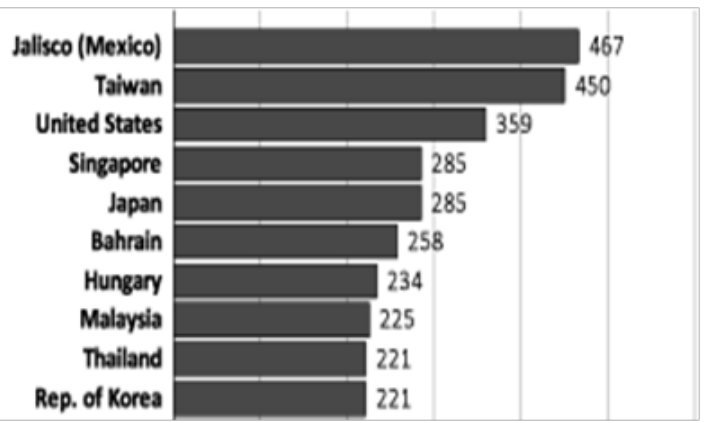

Figure I Incidence rate of ESRD (per million populations) for the top 10 countries in 2012 [7].

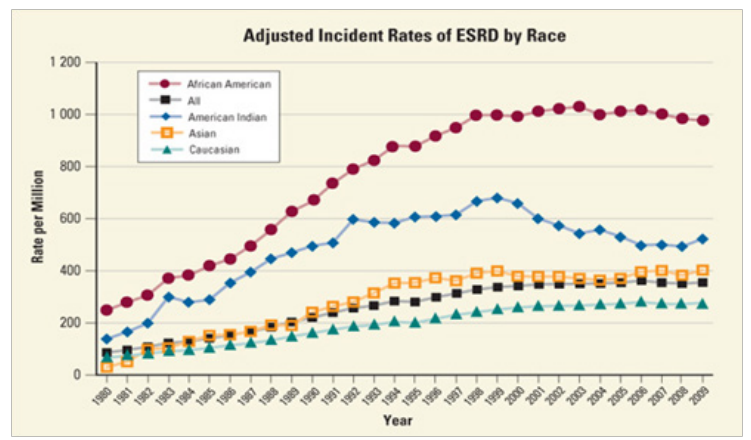

Figure 3 Adjusted incident rates of ESRD by race [9].

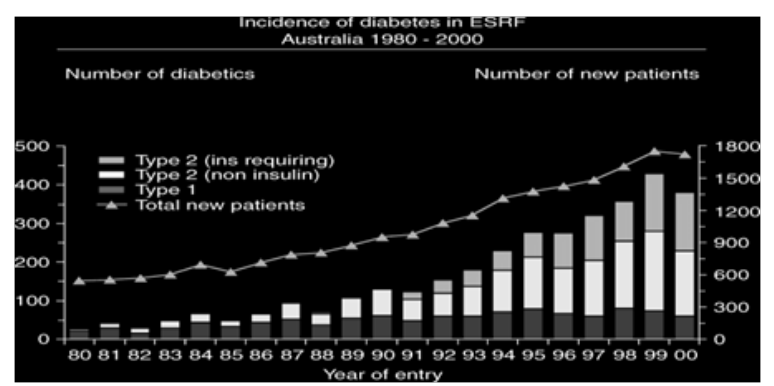

Figure 5 Incidence of diabetes in ESRF Australia 1980-2000 [2].

In developed countries, CKD is normally associated with old age, diabetes, hypertension, obesity, and cardiovascular disease; diabetic than three times higher for African Americans than for Caucasians (Figure 3). ${ }^{9}$ The major cause of ESRD is diabetes and hypertension. Over the decades the United States Renal Data System (USRDS) figures demonstrates a progressive increase in the number of diabetics entering End Stage Renal Failure (ESRF) programs. About $44 \%$ of all incidence patients are diabetics. Glomerulonephritis and cystic kidney disease also remain relatively steady as a cause of ESRD. ${ }^{7}$ Diabetes is the major cause of ESRD worldwide, in both developing and developed countries (Figure 4). In Australia the incidence of ESRD due to diabetes is about 25\% (Figure 5) as well in European Union registry, the number of diabetics entering ESRF programs is about $15 \%-33 \%$ while the number entering due to glomerulonephritis is about $9 \%-20 \%$. $^{10-11}$

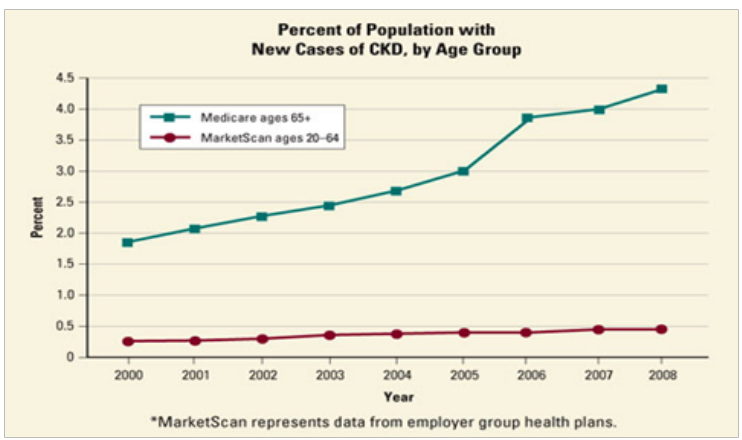

Figure 2 Percentage of population with new cases of CKD, by age group [9].

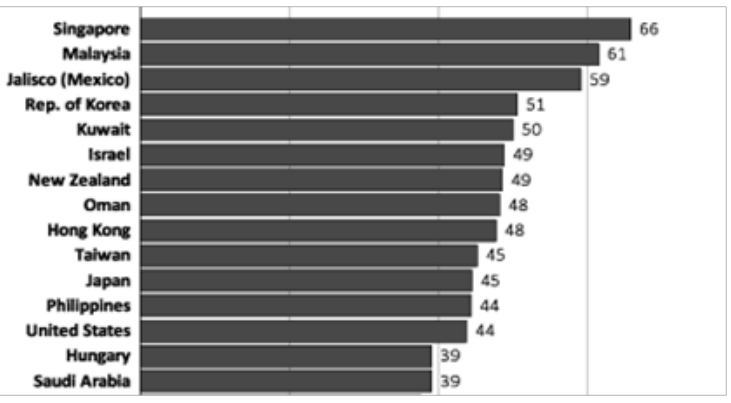

Figure 4 Percentage of incident ESRD patients with diabetes as the primary ESRD cause for the top 15 countries in 2012 [7].

glomerulosclerosis and hypertensive nephrosclerosis are the presumed pathological finding; the exact diagnosis is however often difficult. In developing countries, common causes of CKD also include glomerular and tubule-interstitial diseases due to infections and exposure to drugs and toxins. ${ }^{12}$ Sub-Saharan Africa is a vast heterogeneous region of roughly 47 countries and more than 900 million people. By 2030, more than $70 \%$ of patients with end-stage renal disease are estimated to be living in low-income countries, such as those in sub-Saharan Africa. There are many potential causes of CKD in sub-Saharan Africa, making kidney disease especially burdensome in the region. In addition to non-communicable diseases, communicable diseases such as infectious glomerulonephritis, schistosomiasis, leishmaniasis, and HIV infection are common and can cause CKD. Because more than 22 million people in sub-Saharan Africa have HIV, the potential for an overwhelming burden of CKD in the region is high. ${ }^{13}$
Citation: Sanyaolu A, Okorie C,Annan R, et al. Epidemiology and management of chronic renal failure: a global public health problem. Biostatistics Epidemiol Int J. (20 I8); I ( I): I I-16. DOI: 10.3088 I/beij.00005 
Among the general population in Africa (Figure 6), CKD prevalence was reported to range from $2 \%$ to $41 \%$ (pooled estimate: $16.5 \%$ ) in the West/Central-West, in the Central region the prevalence ranged from $12 \%$ to $17 \%$ (pooled estimate: $16 \%$ ), in the Southern region the CKD prevalence range was $6 \%-29 \%$ (pooled estimate: $12.2 \%$ ), in the Eastern region, the prevalence ranged from $7 \%$ to $15 \%$ (pooled estimate: $11.0 \%$ ), and in the North region, the prevalence ranged from $3 \%$ to $13 \%$ (pooled estimate: $4 \%$ ). In sub-Saharan Africa, the prevalence ranged from $2 \%$ to $14 \%$ (pooled prevalence: $14.02 \%$; $95 \%$ CI $13.5 \%$ to $14.5 \%) .{ }^{14}$

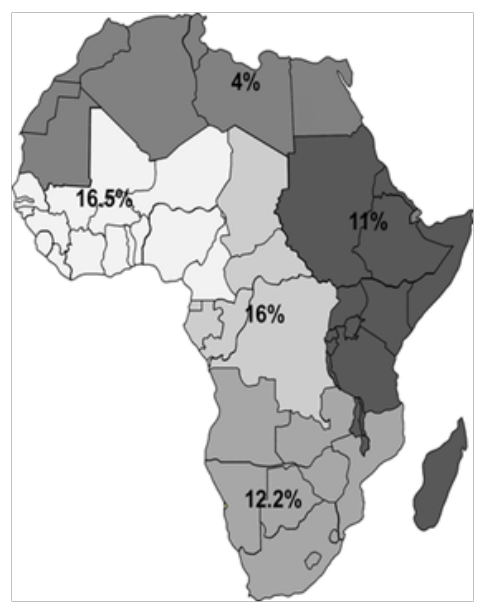

Figure 6 Prevalence of chronic kidney disease among the entire general population. Estimates from this figure should be presented with caution as it is bound to be imprecise and inaccurate due to its tentative way of estimation. ${ }^{14}$

\section{Classification and staging}

The Kidney Disease Outcomes Quality Initiative (KDOQI) of the National Kidney Foundation (NKF) defines chronic kidney disease (CKD) as kidney damage (structural or functional) or a decreased glomerular filtration rate (GFR) of less than $60 \mathrm{~mL} / \mathrm{min} / 1.73 \mathrm{~m}^{2}$ for 3 or more months. ${ }^{15} \mathrm{KDOQI}$ has also established a five-stage classification system of $\mathrm{CKD}$, which is based mainly on glomerular filtration rate (GFR) (Table 1). New equations that show enhanced precision and accuracy of GFR have been developed, such as the Chronic Kidney Disease Epidemiology Collaboration equation. GFR can be estimated using creatinine and cystatin C. Estimating GFR using creatinine alone has been shown to over diagnose $\mathrm{CKD}$ and it has been proposed that combination creatinine-cystatin $\mathrm{C}$ equation performed better than either of these markers alone. ${ }^{15}$ Risks of complications at any given GFR are modified by the amount of proteinuria and KDOQI has implemented the inclusion of both estimated GFR and albuminuria. In stage 1, the kidney function is normal with other evidence of kidney disease, in stage 2 , the function is mildly reduced and in stage 3 eGFR is approximately $30-60 \%$. In stages 1 to $3 \mathrm{CKD}$ should be confirmed with other diagnostic evidence proteinuria or hematuria, a genetic diagnosis of kidney disease (polycystic kidney disease) or evidence of structurally abnormal kidneys (reflux nephropathy), medication review (nephrotoxic drugs) and imaging to exclude obstruction. Patients in stages 1 to 3 can be managed in primary care with aim in reduction of associated risks, such as cardiovascular events, the risk of which is increased with CKD. The risk of cardiovascular death is much higher than the risk of the patient needing dialysis or a renal transplant. Patients should be advised on smoking and lifestyle changes and cholesterol lowering therapy should be considered if there is already a presence of macrovascular disease. In stages 4 and 5 clinical manifestations of CKD are apparent due to low kidney function and patients should be promptly seen by kidney specialist with very low GFR $\left(<15 \mathrm{~mL} / \mathrm{min} / 1.73 \mathrm{~m}^{2}\right)$ or very high albuminuria (>300 mg/24 hours). ${ }^{15-17}$

Table I Stages of chronic kidney disease according to Kidney Disease Outcomes Quality Initiative (KDOQI) ${ }^{17}$

\begin{tabular}{lll}
\hline Stage & Description & GFR $\left(\mathbf{m L} / \mathbf{m i n} / \mathbf{1 . 7 3} \mathbf{~ m}^{\mathbf{2}}\right)$ \\
\hline 1 & $\begin{array}{l}\text { Kidney damage with normal or } \\
\text { increased GFR }\end{array}$ & $>90$ \\
2 & Mild reduction in GFR & $60-89$ \\
3 & Moderate reduction in GFR & $30-59$ \\
4 & Severe reduction in GFR & $15-29$ \\
5 & Kidney Failure & $<15$ \\
\hline
\end{tabular}

\section{Signs and symptoms}

Signs and symptoms of CKD develop over time if kidney damage progresses slowly. Both signs and symptoms of kidney disease are often nonspecific, and can be caused by other illnesses. Due to the kidneys high adaptability to compensate for lost function; signs and symptoms may not appear until irreversible damage has occurred. The early symptoms and CKD are the same for many other illnesses. ${ }^{18}$ The signs and symptoms of kidney disease can be seen in Table 2 .

Table 2 Signs and symptoms of kidney disease

\begin{tabular}{|c|c|c|}
\hline $\begin{array}{l}\text { Early stages of renal } \\
\text { failure }\end{array}$ & $\begin{array}{l}\text { Kidney function } \\
\text { worsening }\end{array}$ & $\begin{array}{l}\text { End stage renal } \\
\text { failure }\end{array}$ \\
\hline Appetite loss & $\begin{array}{l}\text { Abnormally light or } \\
\text { dark skin }\end{array}$ & $\begin{array}{l}\text { Anemia (may begin } \\
\text { earlier) }\end{array}$ \\
\hline $\begin{array}{l}\text { Fatigue and } \\
\text { weakness }\end{array}$ & Drowsiness & $\begin{array}{l}\text { Difficulty breathing } \\
\text { (fluid in lungs) }\end{array}$ \\
\hline Pruritis and dry skin & Numbness & Nocturia \\
\hline Nausea & Breath odor & $\begin{array}{l}\text { Swelling and puffiness } \\
\text { of feet and ankles }\end{array}$ \\
\hline $\begin{array}{l}\text { Weight loss without } \\
\text { trying to lose weight }\end{array}$ & Frequent hiccups & High blood pressure \\
\hline $\begin{array}{l}\text { Decreased mental } \\
\text { sharpness }\end{array}$ & Blood in stool & $\begin{array}{l}\text { Changes in menstrual } \\
\text { cycle }\end{array}$ \\
\hline $\begin{array}{l}\text { Muscle twitching, } \\
\text { cramps }\end{array}$ & Problems sleeping & Poor digestion \\
\hline
\end{tabular}

\section{Differential diagnosis}

The differential diagnosis with CKD is a challenge owing to the overlapping clinical features. Making the distinction between CKD can be very difficult. A history of chronic kidney disease is usually silent. Therefore, differential diagnosis relies heavily on laboratory evaluation and diagnostic imaging. Nonetheless, a careful history and examination will often reveal clues to the correct diagnosis. Differential diagnosis includes acute kidney injury, diabetic neuropathy, glomerulonephritis, nephritic syndrome and systemic lupus erythematosus. ${ }^{19}$ 


\section{Pathophysiology}

Briefly, chronic renal failure is characterized by a gradual loss of kidneys function. The kidneys function as the body main excretory organs eliminating the body's metabolic waste products by filtering blood. Substances that are unneeded or present in excess are filtered out of the blood and forming the urine. By adjusting the blood composition, the kidneys are able to maintain blood volume and pressure, ensuring a balance of Sodium $\left(\mathrm{Na}^{+}\right)$, Chloride $(\mathrm{Cl}$ ), Potassium $\left(\mathrm{K}^{+}\right)$, Calcium $\left(\mathrm{Ca}^{2+}\right)$, Hydrogen $\left(\mathrm{H}^{+}\right)$and $\mathrm{pH}$ and eliminating urea, uric acid and creatinine. ${ }^{12}$

\section{Treatment and management}

Once there is diagnosis of chronic renal failure, there is an attempt to determine the cause and put into practice a specific treatment plans. Nonspecific plans can be implemented to delay or possibly arrest the progressive loss of kidney function.

\section{Non-specific treatment plans}

Control hypertension: Controlling hypertension is important to slow the progression of kidney damage. ACE inhibitor class of antihypertensive drugs is preferably used because of its protective effect on kidney. The main target of the treatment is to bring the blood pressure down to the range of systolic 120 to $135 \mathrm{~mm}$ of $\mathrm{Hg}$ and diastolic pressure of 70 to $80 \mathrm{~mm}$ of $\mathrm{Hg}$. Two meta-analyses have looked at the effect of adding ARB treatment to ACE inhibitors in patients with CKD. These show that combination treatment reduces proteinuria $(\geq 0.5 \mathrm{~g} /$ day, approximately equivalent to a protein/ creatinine ratio of $50 \mathrm{mg} / \mathrm{mmol}$ ) more than ACE inhibitor alone in both patients with diabetic and non-diabetic kidney disease. ${ }^{20}$

Restrict dietary protein: Dietary protein is broken down into amino acids and absorbed from the stomach into blood. Our body use amino acid to build muscle and perform other essential functions. Excess amino acids are broken down into carbohydrate and nitrogencontaining waste that is eliminated by the kidneys. More intake of dietary protein intake means more jobs for the kidney eliminating the more waste products. This process may further damage kidney and speed up the Progression of CRF. ${ }^{20}$

Manage pre-end-stage renal disease (pre-ESRD): Treatment of preESRD should begin once the GFR drops below $30 \mathrm{ml} / \mathrm{min}$. Anemia often develops because the kidneys produce an inadequate amount of erythropoietin (EPO). Erythropoiesis stimulating agents should be considered in all patients with anemia of CRF to improve their quality of life. In patients with chronic kidney disease treated with erythropoiesis stimulating agents (epoetins) the hemoglobin should normally be kept between $100 \mathrm{~g} / \mathrm{l}$ and $120 \mathrm{~g} / \mathrm{l}$ with a warning not to exceed a concentration of $120 \mathrm{~g} / \mathrm{l}^{20}$

Identify and treat secondary hyperparathyroidism: Secondary hyperparathyroidism can occur when the parathyroid glands over produce parathyroid hormone in an attempt to help the body to increase the amount of calcium in the blood..$^{19}$ The patient cannot absorb enough calcium in their diet and there is loss of control of calcium and phosphorus. Patients with secondary hyperthyroidism should restrict dietary phosphorus intake when phosphate or parathyroid hormone levels begin to rise. ${ }^{20}$ Most patients require a potent vitamin D supplement, which will help suppress excess PTH production.
Cinacalcet hydrochloride may be used alone or in combination with vitamin D supplements or phosphate-binders to treat patients with secondary hyperparathyroidism who are on dialysis. ${ }^{21-22}$

Relieve swelling: Retention of fluids is common in chronic renal failure. This can lead to swelling in the legs and ankles. When the kidneys cannot keep up with waste and fluid clearance on their own, they may fail near completely or completely. Different procedures involved in Renal Replacement Therapy (RRT) include:

\section{Specific treatment plans}

Hemodialysis: Removal of toxic elements from the blood by filtering blood through a membrane while circulated outside of the body.

Peritoneal dialysis: A catheter is inserted into the abdomen, fills the peritoneal cavity with a dialysis solution that absorbs waste and excess fluids. Waste products are filtered through the lining membrane of the abdominal cavity. After a period of time, the dialysis solution drains from the body carrying the waste materials.

Kidney transplantation: Kidney transplants involve surgically replacing a healthy kidney from a donor and removing damaged kidney of the CRF patient. Transplanted kidneys can come from deceased or living donors. Patients will require medication for the duration of life to prevent the new kidney from being rejected. ${ }^{20-22}$ At $85.5 \%$, the 5-year survival rate for transplant patients is more than twice the $35 \%$ survival rate for dialysis patient (Figure 7). In the United States, it is estimated that perhaps 6,000 persons whose life spans could be appreciably prolonged through treatments already known, die every year from chronic renal disease. Majority of these people are 15-54 years old. Currently, it is estimated that approximately $1,000-1,100$ receive available treatment, 850 are on dialysis and 150-200 receive kidney transplants annually. ${ }^{9}$

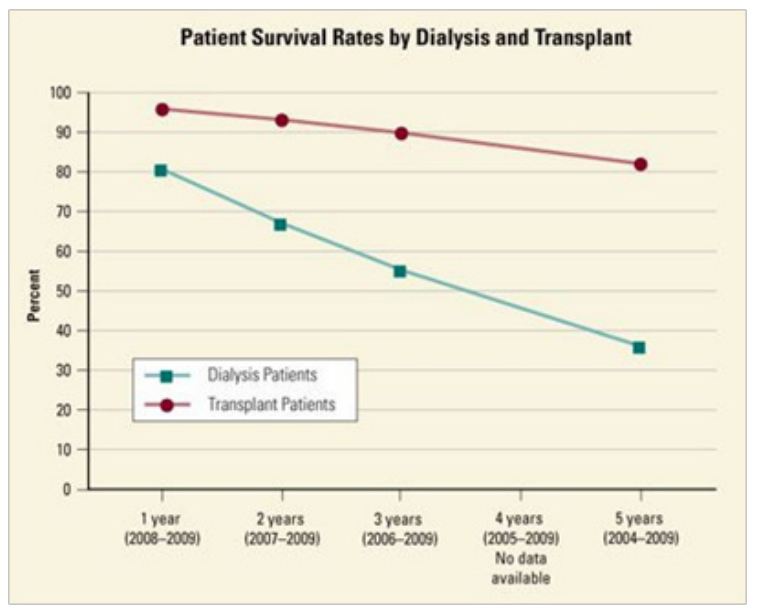

Figure 7 Patient survival rates by dialysis and transplant graph [9].

\section{Current and future research in disease prevention and management of CKD}

When attempting to treat chronic kidney failure, many efforts are used to help diagnose and treat the underlying cause(s). However, when the kidneys are failing due to some of the previously mentioned causes, 
laboratory tests can help determine kidney function and allow for early diagnosis and prevention, and reversal of complications before progression to chronic renal failure.

Many researchers are focusing on identifying genetic markers that may help predict those who may be at risk of developing kidney damage by observing key biochemical pathways. ${ }^{23}$ This mechanism can be valuable element in allowing for early detection and diagnosis of the disease process. If the disease is caught in its early stages, this will permit effective treatment plans with improved outcomes and increased prevention of the disease. One of the ways researchers are looking to provide additional years without dialysis for CKD patients is to treat and manage the diabetes and hypertension from a very early stage. ${ }^{24}$

Lifestyle modifications for individuals that are at risk and management programs for patients currently suffering from disease, can then lead to a decreased number of individuals progressing to the advanced/ chronic and irreversible stage. Programs are available to screen individuals based on factors such as race, family history of chronic renal failure, as well as individuals aged older than $60 .{ }^{25}$ Current research in regards to better strategies being used to prevent scarring includes using immunosuppressive therapy. ${ }^{25}$ Overall there are many ways to diagnose and treat patients who may acquire chronic kidney failure. Current researches with various drugs are in the beta testing stage. Researchers are now looking at these drugs in order to help minimize fibrosis of the kidneys which contributes to the failing of the kidneys. ${ }^{24}$ Researchers are looking into whether or not more frequent dialysis treatments improve function of kidneys, as well as the cardiovascular system long term. For patients undergoing hemodialysis regularly, there are many ways in which scientists are looking to use a fistula in order for the body to have access to a constant pool of blood. Kidney transplantation always remains an option, however chronic regeneration often comes into play and the patient often ends up losing the transplant. ${ }^{26}$ On the public health approach, there is the need for more research efforts aimed at measuring and tracking the CKD burden, identifying at risk populations, as well as targeting program efforts. ${ }^{27}$

\section{Discussion and conclusion}

Incidence of ESRD is on the increase worldwide at an annual growth rate of $8 \%$, far more than the population growth rate of $1.3 \%$. Only about $15 \%$ of the world populations are receiving hemodialysis worldwide, with about $80 \%$ being treated in Europe, North America, and Japan. Only about twenty percent receive treatment in 100 developing countries which make up over $50 \%$ of world population, with some proportion of those living in the poorest countries dying of uremia due mainly to absence of renal replacement therapy. ${ }^{28}$ CKD issues extends beyond a clinical problem that can be addressed only by health care providers to a major public health issue that demands multilevel efforts because CKD is not being diagnosed early enough to initiate treatment regimens and reduce death and disability; also several interventions are being delivered too late to improve population-based outcomes and most individuals with the disease are unaware of having this disorder; hence, there is the need to make health care providers and the general population more aware of the seriousness of the disease, its risk factors, and opportunities for screening. Those identified with the diseases should be provided with appropriate education that explains the treatment regimens and the benefits of undertaking therapy. ${ }^{27}$
Other early intervention includes reducing obesity, hypertension, diabetes and indiscriminate use of non-steroidal anti-inflammatory drugs. At the primary health care level, a proactive approach is required that will help in early detection of the disease. Hence providing adequate nephrology services as well as taking measures to achieve a quantum leap in cadaver kidney donation is essential for affected population. ${ }^{29}$ The burden of CKD, as measured by human suffering and economic costs, is on the rise; thus a comprehensive public health approach is required..$^{30}$

Chronic renal failure is a global issue. While there is still no cure, it is evident that further funding and research is needed to understand the disease, create enhanced screening tools and methods, and education so more can be learned in hopes of better prevention and an ultimate cure.

\section{Conflict of interest}

The authors wish to declare no conflicts of interest.

\section{References}

1. Yach D, Hawkes C, Gould CL, et al. The global burden of chronic diseases: overcoming impediments to prevention and control. JAMA. 2004;291(21):2616-2622.

2. Atkins RC. The epidemiology of chronic kidney disease. Kidney Int Suppl. 2005;67:S14-S18.

3. Couser WG, Remuzzi G, Mendis S, et al. The contribution of chronic kidney disease to the global burden of major noncommunicable diseases. Kidney Int. 2011;80(12):1258-1270.

4. https://emedicine.medscape.com/article/238798-clinical

5. Obrador GT, Pereira BJ, Kausz AT. Chronic kidney disease in the United States: an underrecognized problem. In: Semin Nephrol. Elsevier. 2002;441-448.

6. Jha V, Garcia-Garcia G, Iseki K, et al. Chronic kidney disease: global dimension and perspectives. Lancet. 2013;382(9888):260-272.

7. https://www.usrds.org/2014/view/img_v2_10.html

8. National Institutes of Health. Kidney disease statistics for the United States. Washington, DC. 2016.

9. National Institutes of Health. Kidney Disease Statistics for the United States. Washington, DC. 2012.

10. McDonald SP. Australia and New Zealand dialysis and transplant registry. Kidney Int Suppl. 2015;5(1):39-44.

11. Stel VS, Kramer A, Zoccali C, et al. The 2007 ERA-EDTA registry annual report - a precis. NDT Plus. 2009;2(6):514-521.

12. Levey AS, Coresh J. Chronic kidney disease. Lancet. 2012;379(9811):165-180.

13. Stanifer JW, Jing B, Tolan S, et al. The epidemiology of chronic kidney disease in sub-Saharan Africa: a systematic review and meta-analysis. Lancet Glob Health. 2014;2(3):e174-e181.

14. ElHafeez SA, Bolignano D, D'Arrigo G, et al. Prevalence and burden of chronic kidney disease among the general population and high-risk groups in Africa: a systematic review. BMJ Open. 2018;8(1):e015069.

15. Levey AS, Eckardt K-U, Tsukamoto Y, et al. Definition and classification of chronic kidney disease: a position statement from Kidney Disease: Improving Global Outcomes (KDIGO). Kidney Int. 2005;67(6):2089-2100. 
16. Levey AS, Eckardt K-U, Tsukamoto Y, et al. Definition and classification of chronic kidney disease: a position statement from Kidney Disease: Improving Global Outcomes (KDIGO). Kidney international. 2005;67(6):2089-2100.

17. Inker LA, Schmid $\mathrm{CH}$, Tighiouart $\mathrm{H}$, et al. Estimating glomerular filtration rate from serum creatinine and cystatin C. $N$ Engl J Med. 2012;367(1):20-29.

18. http://www2.kidney.org/professionals/KDOQI/guidelines_ckd/p9 approach.htm

19. http://www.mayoclinic.org/diseases-conditions/chronic-kidney-disease/ symptoms-causes/syc-20354521

20. Rolfo A, Attini R, Nuzzo AM, et al. Chronic kidney disease may be differentially diagnosed from preeclampsia by serum biomarkers. Kidney Int. 2013;83(1):177-181.

21. Stevens PE, O’Donoghue DJ, de Lusignan S, et al. Chronic kidney disease management in the United Kingdom: NEOERICA project results. Kidney Int. 2007;72(1):92-99.

22. http://www.sign.ac.uk/assets/sign103.pdf

23. Ramage IJ, Durkan AM. Principles of management in chronic rena failure. Paediatr Child Health. 2003;13(7):496-501.
24. Klarman HE, Rosenthal GD. Cost effectiveness analysis applied to the treatment of chronic renal disease. Med Care. 1968;6(1):48-54.

25. Coca SG, Singanamala S, Parikh CR. Chronic kidney disease after acute kidney injury: a systematic review and meta-analysis. Kidney Int. 2012;81(5):442-448.

26. Bucaloiu ID, Kirchner HL, Norfolk ER, et al. Increased risk of death and de novo chronic kidney disease following reversible acute kidney injury. Kidney Int. 2012;81(5):477-485.

27. Hallan SI, Stevens P. Screening for chronic kidney disease: which strategy? J Nephrol. 2010;23(2):147-155.

28. Jacobson S. Chronic kidney disease--a public health problem? Lakartidningen. 2013;22;110(21):1018-1020.

29. Schieppati A, Remuzzi G. Chronic renal diseases as a public health problem: epidemiology, social, and economic implications. Kidney Int. 2005;68:S7-S10.

30. Bhowmik D, Pandav CS, Tiwari SC. Public health strategies to stem the tide of chronic kidney disease in India. Indian J Public Health. 2008;52:224-229.

31. Schoolwerth AC, Engelgau MM, Hostetter TH. A public health action plan is needed for chronic kidney disease. Adv Chronic Kidney Dis. $2005 ; 12(4): 418-423$. 